\title{
Review on: "Android Application for Faculties of Higher and Technical Education"
}

\author{
Mr Chavan Vishvajit V'1, Dr. Kulkarni R. V² \\ 1Department of M.Phil, ${ }^{2}$ Professor and Head \\ ${ }_{1,2}$ Chhatrapati Shahu Institute of Business Education and Research, Kolhapur, Maharashtra, India
}

\begin{abstract}
Organised By:
Management Department, Chhatrapati Shahu Institute of Business Education and Research, Kolhapur, Maharashtra

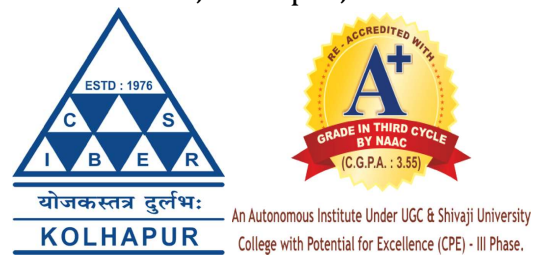

How to cite this paper: Mr Chavan Vishvajit V | Dr. Kulkarni R. V "Review on: "Android Application for Faculties of Higher and Technical Education"'" Published in International Journal of Trend in Scientific Research and Development (ijtsrd), ISSN: 2456-6470, Special Issue | Fostering Innovation, Integration and Inclusion Through Interdisciplinary

Practices in

Management, March 2019, pp.203-206, URL:

https://www.ijtsrd.c om/papers/ijtsrd23 102.pdf

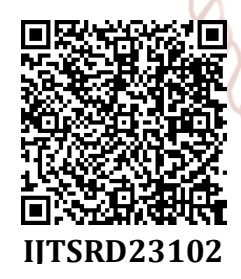

\section{ABSTRACT}

Though this is an era of Information Technology, teachers have to do lots of paper work, always keeping number of copies of documents in both hard copies as well as soft copies. Though when the need arises there is always new searching and preparation of documents. Though teachers are bound to deal with academic diaries or course files filling application for leave, examination related duty, going through the time table etc. Now day's android applications are widely used in every field. The organizations that have websites, desktop applications are also prefer to easiness in functioning of various business activities. With Android applications, teachers can do various functions; vizleave management, workload adjustments, and store and view results, keep FDP/workshop records, will also have smooth functioning of daily work, store important documents, communicate within staff and also follows organizational work structure. This paper focuses on the use of Android Application for teaches in order to fulfill the expectations of institutions like UGC, NAAC etc., about making use of ICT in teaching-learning process, making academic details available in electronic form.

\section{KEYWORDS: Teachers, Android App, Higher-technical education, ICT}

\section{INTRODUCTION}

Now day's android applications are widely used in every field. The organizations that have websites, desktop applications are also prefer to easiness in functioning of various business activities. These applications are well connected with the main system. Android applications for teachers will also have smooth functioning of daily work, store important documents communicate within staff and also follows organizational work structure. Mobile application for teachers would have the functionalities which they are doing manually.
It will have Academic diary, course file or personal file in electronic form. Teachers can do various functions; viz- leave management, workload adjustments, and store and view results, keep FDP/workshop records. Hence this Android App will make available of academic related data with teachers. It also decrease the task of searching for docs, certificate etc.

\section{LITERATURE REVIEW}

Though there are various applications are developed for teachers, which include desktop and web applications, but very rare development is found dedicated to teachers use. Following are the summarized reviews in the related research area.

1. "Course File Management System IJCSN International Journal of Computer Science and Network, 2014" This research paper gives an idea of implementation of "course file management system" for teachers. It is desktop application. The archiving system for course files is very important for all and the main aim of this system is to solve the problems related to submission the files by hand from faculty members to the Committees of Academic Accreditation. The system contributes significantly to save time and efforts of the faculty members and committees. The members in the faculty can access the system easily and upload the required files during the semester without waiting until the end of the semester. The system will allow the members of the committee to write notes on the files delivered to them after reviewing as well as the system will send SMS to faculty members to remind them in case of delay in submission of requested files. The program will also save time and effort of the employees in submitting the files by hand. The main advantage of this project is to design quick and easy user interface for use by accreditation committees, the faculty members in 
accordance with the specific authorities for submitting the files of courses and reviewing them.

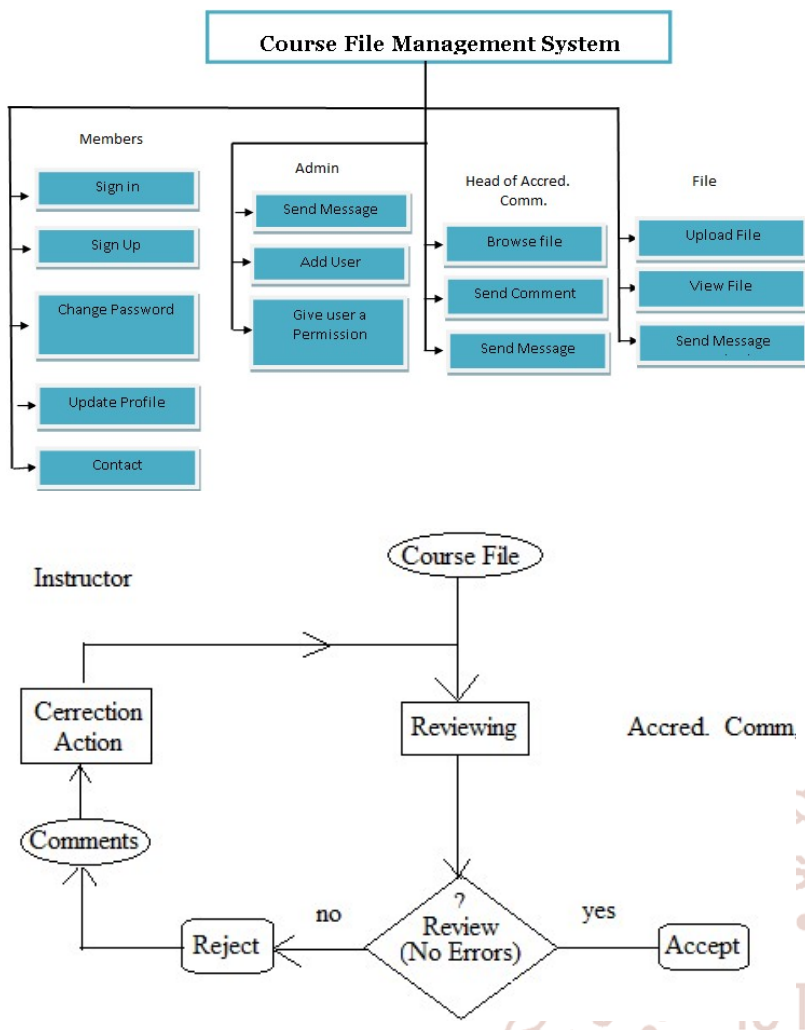

2. "An e-Course file management system: A green campus initiative,2013".In this paper the author, as a green campus initiative, he propose a prototype e-course file database management system to compile and organize the course files via user friendly graphical user interfaces. Here the author proposes the desktop system. The paper-based course files maintained manually present a variety of disadvantages that include physical storage, retrieval issues, and recurring paper and printing costs. Moreover, the extensive paper usage required to maintain course files poses negative environmental impacts occurring during the paper making and disposal stages of paper life-cycle. This system would also eliminate the storage and financial costs and would reduce the man-hours spent on preparing the paper-based course files. This will reduce the burden on the natural resources which is the ultimate target of green initiatives in different types of organizations for achieving a sustainable clean environment. The system will also allow the different stakeholders to view and assess the course files from their desktops.

\section{eCourse File Management System Course Selection Form}

\begin{tabular}{l|l|l|} 
Select Semester: & Fall $2012-12$ \\
Select Course: & & \\
& & Submit
\end{tabular}

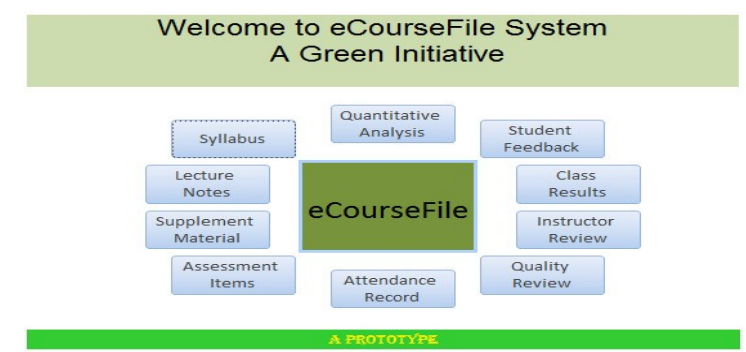

3. "Design and Implementation of Web-Based Document Management Systems" published by IEEE reveals the design and implementation of two web-based document management systems customized to serve the need of an international organization. The systems were designed to replace a paper-based process that gradually became unmanageable due to the increasingly large volume of texts and the need to distribute the documents to geographically remote locations. Features of the new systems include online recording of forms and texts, automatic email notifications and reminders, electronic authorization, database query functions, a secure mechanism for web access of documents for approval and future references. It is described here the design principles and introduced the functional modules in each system. Systems were implemented on Windows and UNIX platforms using open-source software such as PHP4, MySQL, Apache, etc.

4. "Introducing Dynamic Mathematics Software to Secondary School Teachers: The Case of GeoGebra" In this paper a study aimed to identify most common impediments related to the introduction of an opensource mathematical software package GeoGebra. This application generates the report based on analysis of data collected during a three-week professional development programme organized for middle and high school teachers in Florida. The study identified challenges participants face during workshops and evaluated the difficulty levels of GeoGebra tools. Findings of the study, complexity criteria of software tools and commonly occurring difficulties, provided the basis for the development of several new materials assisting workshop activities and contributed to the improvement of introductory GeoGebra workshops.

5. "Barriers to adopting emerging technologies in education" PL Rogers - Journal of educational computing research, 2000 This article examines barriers to technology adoption based on the literature and data from two studies. A five-step hierarchical model. It isfamiliarization, utilization, integration, reorientation and evolution of adoption of technology in the classroom is presented, and internal and external barriers to technology adoption are examined. The two studies are then described. In the K-12 study, 1,000 art teachers were surveyed to: ascertain current levels of technology adoption; characterize teaching strategies used for learning in computer-based art classrooms; identify barriers to technology adoption; and propose an instructional model. In the second study, information on the impact of a large-scale initiative, the Electronic Academy, implemented at two- and four-year institutions in a Midwestern state postsecondary system, was collected from instructional technology 
International Journal of Trend in Scientific Research and Development (IJTSRD) @ www.ijtsrd.com eISSN: 2456-6470

coordinators. A product of this examination is a visual representation of the interactions and interdependence of elements that contribute to the construction of barriers to technology adoption. Three tables contain a summary of research on barriers to technology adoption and data on barriers to technology adoption at the elementary, secondary, and postsecondary levels.

\begin{tabular}{lccc}
\multicolumn{5}{c}{ Barriers to Technology Adoption at the Post-secondary Level } \\
\hline Interviews Completed: & $\begin{array}{c}\text { Technical and } \\
\text { Community } \\
\text { Colleges }\end{array}$ & State Universities & Total \\
& $(21)$ & $(7)$ & 28 \\
\hline 1. Need technical support & 11 & 6 & 17 \\
staff & $52 \%$ & $86 \%$ & $61 \%$ \\
\hline 2. Need release time and time & 11 & 3 & 14 \\
for training faculty and staff & $52 \%$ & $43 \%$ & $50 \%$ \\
\hline 3. Funds not specified for & 13 & 6 & 19 \\
technology-related needs & $62 \%$ & $86 \%$ & $68 \%$ \\
\hline 4. Lack of sharing best & 14 & 3 & 17 \\
practices across system & $67 \%$ & $43 \%$ & $61 \%$
\end{tabular}

6. Google Classroom. https://classroom.google.com/h This is mobile app of the G Suite for education. This is used by the school for the purpose of distributing and grading the assignments of the students. This app facilitates the teachers for storing the class materials in $\mathrm{G}$ drive so that the students can have an easy access to the materials in case of urgent requirements. The teachers also use this app for making certain announcements and debates.

7. The Teacher App; http://www.theteacherapp.org/. about is a free app to help teachers learn and grow anytime, anywhere at zero cost. The Teacher App is a platform where every teacher in India can access high. quality content to learn and grow anytime, anywhere, at zero cost using a smart phone. With The Teacher App, we get access to courses, educational resources, stories and conversations. This App offers-Free, easy-to-use, downloadable course content which is taught in class. It also has an access to experts from the Indian education system. It also facilities of sharing classroom stories, and experiences of teachers all over India. This app also have an scope to classroom innovations, methods and resources adopted by teachers.

8. my diary system, http://www.myediary.com.au This system Equip teachers with the best resource of all. Time. With homework management, class communication and parent conversations managed within My Diary, teachers have more time to actually teach. The main modules for teachers are-notifications, student progress, time table and calendar and teacher planner. It also has provision for students and parents to participate together in teaching learning activities. Parents can start conversations with their child's teachers, can communicate within the context of the diary. Parents can see their child's homework deadlines, details and attachments. parents can receive announcements, newsletters, permission slips, school policy information and notices. Students can access their timetable, school and class announcements, events, reminders and homework tasks.

\section{Research Gap}

The researcher has reviewed the various research articles and android applications. These applications are built for faculties and students and development of mobile applications. These apps are also act as bridge between school teachers and their development. Researcher also found that there are many desktop applications made for faculties of colleges and universities. So based on this it is found that is very rare development have been carried out related mobile application for faculties in higher and technical education. It is also observed that there is less applications are developed for teachers to manage their daily work, course files or academic diary etc. Hence to facilitates the teachers for their routine educational work topic is finalized as "Development and Implementation of Android Application for Faculties of Higher and Technical Education".

\section{Conclusion}

The application yet developed and proposed for the teachers academic work are desktop or web applications. Using mobile application in daily routine saves times, complete tasks faster, reliable and making information available and any time anywhere. Smart phones, that have become an important part of today's life, have reduced all the efforts. Service quality is the most important dimensions of web channels in order to increase the satisfaction level user. In addition, this online environment offers many relative advantages to user. These relative advantages attract teachers to more convenient, easier, time-saving, and more enjoyable scenario.

\section{V. ${ }^{\text {References }}$}

[1] Course File Management System, IJCSN International Journal of Computer Science and Network, Volume 3, Issue 5, October 2014ISSN (Online): 2277-5420 Impact Factor: 0.274

[2] An e-Course file management system: A green campus initiative ISSN 2224-5758 (Paper) ISSN 2224-896X (Online) Vol.3, No.1, 20133.

[3] Design and Implementation of Web-Based Document Management Systems" Print ISBN: 0-7695-2743-4, Publisher : IEEE

[4] Dynamic Mathematics Software to Secondary School Teachers: the Case of GeoGebra JCMST Volume 28, Number 2, April 2009 ISSN 0731-9258 Publisher. Preiner, J. (2008).

[5] Introducing dynamic Mathematics software to Mathematics teachers: the case of GeoGebra. Phd thesis, 264 pages, university of salzburg, austria schumann, H. (1991). Schulgeometrisches Konstruieren MIT-DEM Computer. Teubner und Metzler, stuttgart.

[6] https://classroom.google.com/h.

[7] http://www.theteacherapp.org/

[8] Oracle Content Management (2009). Go Green With Oracle Content Management. [Online] Available:http://www.oracle.com/us/products/middle ware/content-management/059500.pdf.

[9] Jason Yao and Jessica H. Li, PRACTICAL DESIGN AND IMPLEMENTATION OF WEB-BASED, DOCUMENT 
International Journal of Trend in Scientific Research and Development (IJTSRD) @ www.ijtsrd.com eISSN: 2456-6470

MANAGEMENT SYSTEMS, 10th IEEE International Enterprise Distributed Object Computing Conference Workshops, 2006 (EDOCW'06).

[10] Syed Mushhad Mustuzhar Gilani, Jamil Ahmed, Muhammad Azeem Abbas, Electronic Document Management: A Paperless University Model, 2nd IEEE International Conference on Computer Science and Information Technology, 2009. ICCSIT 2009.
[11] myediary system, http://www.myediary.com.au.

Copyright (C) 2019 by author(s) and International Journal of Trend in Scientific Research and Development

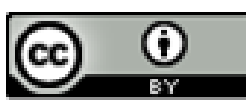
Journal. This is an Open Access article distributed under the terms of the Creative Commons Attribution License (CC BY 4.0) (http://creativecommons.org/licenses/by/4.0) 